\title{
Water Consumption and its Determinants Among Women in Ghana: 2008 Demographic and Health Survey
}

\author{
Clement Kubreziga Kubuga, PhD \\ Ambrose Atosona, MPhil \\ Nutritional Sciences Department, \\ University for Development Studies, Tamale, Ghana \\ Victor Mogre, PhD \\ Department of Human Biology, \\ University for Development Studies, Tamale, Ghana
}

Doi:10.19044/esj.2019.v15n36p267 URL:http://dx.doi.org/10.19044/esj.2019.v15n36p267

\begin{abstract}
Water is one of the most critical nutrients for humans in ensuring good health and well-being. Interestingly, majority of the vulnerable subpopulations of women in Ghana do not meet the daily recommended water intake set by the Ghana's Ministry of Health yet the socio-economic/ demographic factors and dietary patterns influencing water intake are lacking. This study investigated the socio-economic/ demographic factors and dietary patterns influencing water intake. A total of 1,548 women with water and food intake data from the 2008 Ghana Demographic Health Survey (GDHS), which is a representative nationwide cross-sectional study, was used. $83 \%$ of the women did not meet the recommended daily water intake. Of four dietary patterns ('Beverage \& sugary based', 'Meat based', 'Indigenous- tuber based' and 'Indigenous- grain based') emerging, meat based dietary pattern, seasonality, body mass index (BMI), and alcohol consumption emerged as key determinants of water intake. In summary, seasonality, dietary patterns and some key socio-economic/ demographic factors were identified as determinants of water intake. The identified determinants can serve as a basis for nutrition intervention and policies for women in Ghana.
\end{abstract}

Keywords: Water Intake, Women, Ghana

\section{Introduction}

Water is one of the most critical nutrients for humans (Jéquier \& Constant, 2010; Kleiner, 1999; Manz, Wentz, \& Sichert-Hellert, 2002), short term inadequacy or absence of it can be lethal. Several countries and 
multinational organizations have developed water intake recommendations based on national estimates of water intake to ensure adequate water intake at population level (EFSA Panel on Dietetic Products \& Allergies, 2010; Electrolytes \& Water, 2005; Gibson \& Shirreffs, 2013; Organization, 2005). The Institute of Medicine (IOM) recommends 3.3 and 2.3 liters of total water intake per day for men and women respectively while the European Food Safety Authority (EFSA) recommends 2.5 liters of water for men and 2.0 for women (Gandy, 2015). World Health Organization (WHO) on the other hand, recommends 2.2 liters for females and 2.9 liters for males in sedentary temperate environments (Grandjean, 2004). Total water needs can be met by plain drinking-water, beverages, and moisture from foods (Campbell, 2004; Kant, Graubard, \& Atchison, 2009; Vieux, Maillot, Constant, \& Drewnowski, 2016). Generally, it is suggested that plain water and beverages supply much more of total daily water than food moisture (Drewnowski, Rehm, \& Constant, 2013a, 2013b; Stern, Piernas, Barquera, Rivera, \& Popkin, 2014). Additionally, the overall percentage of water intake or water in foods vary between countries and seasons, depend on food types and dietary patterns (Gandy, 2015).

Many countries use only plain water recommendations as water in food is not always available in food composition tables and unavailability of metabolic water (Gandy, 2015). These issues point to the unreliability of total water intake data in population surveys (Gandy, 2015). In Ghana, total water intake is currently lacking and no dietary reference values exist. With limited information on total water intake, the Ministry of Health of Ghana recommends drinking at least 8 glasses of water a day (GSS, 2009). Using this recommendation, only $17 \%$ of the vulnerable subpopulation of women meet the recommended daily water intake (GSS, 2009). Interestingly, socioeconomic/ demographic factors and dietary patterns influencing water intake among Ghanaian women have not previously been explored at the national level. This study utilized the 2008 Ghana Demographic and Health Survey (GDHS) survey data to investigate the socio-economic/ demographic factors and dietary patterns influencing water intake.

\section{Materials and Methods Study design and subjects}

This paper analysed the 2008 GDHS data which is nationally representative. The survey aimed to collect, analyse, and disseminate information on housing and household characteristics, education, maternal health and child health, nutrition, family planning, gender, domestic violence, knowledge and behaviour related to HIV/AIDS (GSS, 2009).

The survey used a two stage sample design based on the 2000 Population and Housing Census to produce estimates for key indicators in 
Ghana. The first stage involved selection of sample, a total of 412 clusters. The second stage of selection involved a systematic sampling of 30 households in each cluster with the aim of ensuring adequate numbers of completed individual interviews. A total of 12,323 households were selected. From these sampling units 11,778 households were interviewed, giving a response rate of $99 \%$.

In half of the households selected for the interview/survey, all eligible women aged 15-49 and all eligible men aged 15-59 were interviewed with the Women's and Men's Questionnaires, respectively. A total of 4,916 women aged 15-49 and 4,568 men aged 15-59 from 6,141 households were interviewed (GSS, 2009). The response rate for the interview for the men and women were 96\% (of 4,769) and 97\% (of 5,096), respectively. Ethical approval for the study was obtained from ICF Macro Institutional Review Board (IRB) in Calverton, Maryland, USA and the Ghana Health Service Ethical Review Committee in Accra, Ghana. Details of the GDHS research design and methods have been published elsewhere (GSS, 2009).

\section{Water and food consumption assessment}

The survey used three types of questionnaires: the household questionnaire, the men's questionnaire and the women's questionnaire. The women's questionnaire was used to obtain information on all women (15-49 yrs). This study used the data gathered from the women's questionnaire. The women's questionnaire included questions on women typical water consumption and food consumption during the day and night preceding the day of the interview. They were specifically asked: How many glasses of water do you drink in one day on average? The food intake questions were only asked to women who had children under the age of 3 years and were living together. In extracting this category of women, Authors had a total of 1548 women in all. Water intake was in glasses, qualitative responses on women were obtained based on their answers ('yes' for consumption or 'no' for nonconsumption) to a pre-determined list of food items.

\section{Statistical analysis}

Data analyses were carried out using SAS 9.4 (SAS Institute Inc., Cary, NC, USA.). Distribution of women typical water intake by socioeconomic/ demographic factors and dietary patterns was examined by Pearson chi-square test. Dietary patterns of the women were identified by subjecting food items reported in SP 1 to principal component analysis (PCA) as the extraction procedure.

Multivariable logistic regression was used to examine the relationship between socio-economic/ demographic determinants, dietary patterns (SP 1) of women and typical water consumption. All the studied covariates were 
simultaneously adjusted in the multiple regression model. Researchers modelled the probability of inadequate water intake ( $\leq 7$ cups of water/day) as the outcome of interest. For the determinants of water intake, consumption in the whole study population was used for the purposes of simplicity. However, the analysis adjusted for sub strata (pregnancy status). Key covariates used included: Number of household members, month of interview, age, body mass index (BMI), religion, ethnicity place of residence, region of residence, wealth index, kind of union, and consumption of alcohol. Statistical significance was set at $\mathrm{P}<0.05$. The results are presented as coefficients with their corresponding p-values. Coefficients have been used as they are easy to interpret.

Table 1. Determinants of inadequate water intake by Ghanaian women: The 2008 Ghana Demographic and Health Survey

\begin{tabular}{|c|c|c|c|c|}
\hline Variable & $\mathrm{n}(\%)$ & Estimate & $\mathrm{SE}$ & $\mathrm{P}$-value \\
\hline \multicolumn{5}{|l|}{ Age in years } \\
\hline $15-25$ & $568(36.8)$ & 0.4 & 0.3 & 0.216 \\
\hline $26-35$ & $687(44.5)$ & 0.2 & 0.3 & 0.513 \\
\hline $36-49$ & $288(18.7)$ & & Ref & \\
\hline \multicolumn{5}{|c|}{ Body mass index (BMI) } \\
\hline Underweight & $115(7.6)$ & 1.9 & 0.6 & 0.002 \\
\hline Normal weight & $1018(67.3)$ & 1.1 & 0.3 & 0.000 \\
\hline Overweight & $293(18.7)$ & 0.5 & 0.3 & 0.119 \\
\hline Obese & $97(6.4)$ & & Ref & \\
\hline \multicolumn{5}{|l|}{ Wealth quintile } \\
\hline Lowest & $474(30.7)$ & -0.3 & 0.5 & 0.578 \\
\hline Second & $346(22.4)$ & -0.2 & 0.4 & 0.514 \\
\hline Middle & $260(16.9)$ & 0 & 0.3 & 0.911 \\
\hline Fourth & $175(17.8)$ & 0.1 & 0.3 & 0.762 \\
\hline Highest & $188(12.2)$ & & Ref & \\
\hline \multicolumn{5}{|l|}{ Kind of union } \\
\hline Monogamy & $1142(78.8)$ & -0.1 & 0.3 & 0.646 \\
\hline Polygamy & $308(21.2)$ & & Ref & \\
\hline \multicolumn{5}{|c|}{ Number of household members } \\
\hline$\leq 4$ members & $573(37.1)$ & -0.3 & 0.2 & 0.098 \\
\hline$>4$ members & $970(62.9)$ & & Ref & \\
\hline \multicolumn{5}{|l|}{ Pregnancy status } \\
\hline Not pregnant & $1437(93.1)$ & 0.5 & 0.3 & 0.168 \\
\hline Pregnant & $106(6.9)$ & & Ref & \\
\hline \multicolumn{5}{|l|}{ Religion } \\
\hline Christians & $1043(71.0)$ & 0.3 & 0.6 & 0.634 \\
\hline Islam & $311(21.2)$ & -0.5 & 0.7 & 0.499 \\
\hline Traditionalist/other & $115(7.8)$ & & Ref & \\
\hline \multicolumn{5}{|l|}{ Region of residence } \\
\hline Southern Ghana & $1032(66.9)$ & 0.1 & 0.5 & 0.841 \\
\hline Northern Ghana & $511(33.1)$ & & Ref & \\
\hline \multicolumn{5}{|l|}{ Place of residence } \\
\hline Urban & $526(34.1)$ & -0.5 & 0.3 & 0.064 \\
\hline Rural & $1017(65.9)$ & & Ref & \\
\hline
\end{tabular}




\section{Results}

\section{Socio-economic/ demographic factors distribution and water intake}

Table 1 (second column) indicates the distribution of the socioeconomic/ demographic factors of women. Key highlights of essence is that majority of the households $(62 \%)$ had a membership of $>4$, most of the households $(31 \%)$ belong to the poorest quintile. Majority of the women $(67 \%)$ had a normal BMI while most of the women $(66 \%)$ lived in rural areas. $20 \%$ of the women consume alcohol and a small fraction of the women $(7 \%)$ were currently pregnant.

Table 1. Continued

\begin{tabular}{|c|c|c|c|c|}
\hline Variable & $\mathrm{n}(\%)$ & Estimate & SE & P-value \\
\hline \multicolumn{5}{|c|}{ Month of interview } \\
\hline September & $608(39.4)$ & 1.1 & 0.3 & $<.0001$ \\
\hline October & $617(40.0)$ & 0.7 & 0.2 & 0.008 \\
\hline November & $318(20.6)$ & & Ref & \\
\hline \multicolumn{5}{|l|}{ Ethnicity } \\
\hline Akan & $597(38.7)$ & -0.6 & 0.7 & 0.350 \\
\hline Ga/Dangme & $69(4.5)$ & -1 & 0.8 & 0.206 \\
\hline Ewe & 202(13.1) & -1.1 & 0.7 & 0.112 \\
\hline Guan & $42(2.7)$ & 0.7 & 1.2 & 0.570 \\
\hline Mole-Dagbani & $386(25.0)$ & -0.1 & 0.7 & 0.920 \\
\hline Grussi & $91(5.9)$ & -0.6 & 0.8 & 0.497 \\
\hline Gruma & $93(6.0)$ & 0.6 & 1.2 & 0.646 \\
\hline Other & $62(4.0)$ & & Ref & \\
\hline \multicolumn{5}{|c|}{ Consumes alcohol } \\
\hline No & $1228(79.6)$ & 0.7 & 0.2 & 0.008 \\
\hline Yes & $314(20.4)$ & & Ref & \\
\hline \multicolumn{5}{|c|}{ Dietary patterns of Ghanaian women } \\
\hline \multicolumn{5}{|c|}{ Beverage \& sugary based } \\
\hline tertile 1 & 498(33.6) & -0.1 & 0.3 & 0.773 \\
\hline tertile 2 & $490(33.0)$ & 0.2 & 0.2 & 0.455 \\
\hline tertile 3 & $495(33.4)$ & & Ref & \\
\hline \multicolumn{5}{|l|}{ Meat based } \\
\hline tertile 1 & $487(32.8)$ & 0.4 & 0.2 & 0.087 \\
\hline tertile 2 & $501(33.8)$ & 0.6 & 0.2 & 0.017 \\
\hline tertile 3 & $495(33.4)$ & & Ref & \\
\hline \multicolumn{5}{|c|}{ Indigenous- tuber based } \\
\hline tertile 1 & $495(33.4)$ & 0.3 & 0.3 & 0.184 \\
\hline tertile 2 & 493(33.2) & 0.3 & 0.2 & 0.185 \\
\hline tertile 3 & $495(33.4)$ & & Ref & \\
\hline \multicolumn{5}{|c|}{ Indigenous- grain based } \\
\hline tertile 1 & $494(33.3)$ & 0.3 & 0.3 & 0.239 \\
\hline tertile 2 & $497(33.5)$ & -0.2 & 0.2 & 0.495 \\
\hline tertile 3 & $492(33.2)$ & & Ref & \\
\hline
\end{tabular}

Dietary patterns were derived from 17 food items/groups: Dark green leafy vegetables ; Bread, rice, noodles, grains/cereals foods; Potatoes, cassava, or other tubers; Meat (beef, pork, lamb, goat); Pumpkin, carrots, squash; eggs; Mangoes, papayas, other vitamin A foods; Other fruits; Liver, kidney, heart, other internal organs; Fish or shellfish (fresh or 
dried); Beans, peas, lentils, legumes and nuts; Cheese, yogurt, other milk products; Oil, fats, butter, products made from them; Tea or coffee; Chocolates, sweets, candies, and pastries; Tinned, powdered or fresh milk

On water intake by sociodemographic characteristics distribution (Table 2), there were no significant differences between pregnant and nonpregnant women, household size, ethnicity, kind of union, and alcohol usage. Older women, women from richer households, and women from urban residencies were more likely to have adequate intake of water daily than younger women, women from poorer households, and women from urban residencies respectively $(\mathrm{p}<0.05)$. Overweight and obese women were more likely to meet the recommended daily intake of water than normal and underweight women. Dietary patterns indicate that women in the upper tertiles of meat based and indigenous-grain based dietary patterns were more likely to meet the recommended daily intake of water than those in the lower tertiles $(\mathrm{p}<0.05)$. Interestingly, women interviewed in November were more likely to meet the recommended daily intake of water than those interviewed in September and October.

Table 2. Number and proportion of Ghanaian women's water consumption by sociodemographic characteristics and dietary patterns: The 2008 Ghana Demographic and Health Surveys

\begin{tabular}{|c|c|c|c|}
\hline & $\begin{array}{l}\text { Water Intake } \\
\leq 7 \text { cups }(\mathrm{n}=1,274) \\
\mathrm{n}(\%)\end{array}$ & $\begin{array}{l}>7(\mathrm{n}=269) \\
\mathrm{n}(\%)\end{array}$ & p-value \\
\hline \multicolumn{4}{|l|}{ Age in years } \\
\hline $15-25$ & 491(86.4) & $77(13.6)$ & \multirow{3}{*}{0.005} \\
\hline $26-35$ & $558(81.2)$ & $129(18.8)$ & \\
\hline $36-49$ & $225(78.1)$ & $63(21.9)$ & \\
\hline \multicolumn{4}{|c|}{ Body mass index (BMI) } \\
\hline Underweight & $105(91.3)$ & $10(8.7)$ & \multirow{4}{*}{$<.0001$} \\
\hline Normal weight & $872(57.6)$ & $146(9.7)$ & \\
\hline Overweight & $218(85.7)$ & $65(14.3)$ & \\
\hline Obese & $59(60.8)$ & $38(39.2)$ & \\
\hline \multicolumn{4}{|l|}{ Wealth quintile } \\
\hline Lowest* & $397(83.8)$ & $77(16.2)$ & \multirow{5}{*}{0.012} \\
\hline Second* & $294(85.0)$ & $52(15.0)$ & \\
\hline Middle* & $223(85.8)$ & $37(14.2)$ & \\
\hline Fourth* & $219(79.6)$ & $56(20.4)$ & \\
\hline Highest & $141(75.0)$ & $47(25.0)$ & \\
\hline \multicolumn{4}{|l|}{ Kind of union } \\
\hline Monogamy & $943(82.6)$ & 199(17.4) & \multirow{2}{*}{0.860} \\
\hline Polygamy & $253(82.1)$ & $55(17.9)$ & \\
\hline \multicolumn{4}{|c|}{ Number of household members } \\
\hline$<4$ members & $463(80.8)$ & $110(19.2)$ & \multirow{2}{*}{0.161} \\
\hline$>4$ members & $811(83.6)$ & $159(16.4)$ & \\
\hline \multicolumn{4}{|c|}{ Pregnancy status } \\
\hline Not pregnant & $1188(82.7)$ & $249(17.3)$ & \multirow[b]{2}{*}{0.687} \\
\hline Pregnant & $86(81.1)$ & $20(18.9)$ & \\
\hline
\end{tabular}




\section{Religion}

Christians

$856(82.1)$

187(17.9)

Islam

264(84.9)

47(15.1)

0.498

Traditionalist/other

94(81.7)

21(18.3)

\section{Region of residence}

Southern Ghana

853(82.7)

$421(82.4)$

$179(17.3)$

90(17.6)

Place of residence

Urban

418(79.5)

108(20.5)

856(84.2)

*P-values based on the Pearson chi-square test.

Table 2. Continued

Water Intake

$$
\begin{array}{ccc}
\leq 7 \text { cups }(\mathrm{n}=1,274) & >7(\mathrm{n}=269) & \mathrm{p} \text {-value } \\
\mathrm{n}(\%) & \mathrm{n}(\%) &
\end{array}
$$

\section{Month of interview}

September

523(86.0)

$85(14.0)$

October

514(83.3)

103(16.7)

$<.0001$

November

237(74.5)

81(25.5)

\section{Consumes alcohol}

No

1025(83.5)

203(16.5)

Yes

248(79.0)

66(21.0)

0.062

\section{Beverage \& sugary based}

tertile 1

408(81.9)

90(18.1)

tertile 2

419(85.5)

71(14.5)

0.125

tertile 3

400(80.8)

95(19.2)

\section{Meat based}

tertile 1

410(84.2)

77(15.8)

tertile 2

425(84.8)

$76(15.2)$

0.037

tertile 3

392(79.2)

103(20.8)

Indigenous- tuber based

tertile 1

412(83.2)

83(16.8)

tertile 2

409(83.0)

84(17.0)

0.869

tertile 3

406(82.0)

89(18.0)

Indigenous- grain based

tertile 1

432(87.5)

62(12.6)

tertile 2

394(79.3)

103(20.7)

0.002

tertile 3

401(81.5)

91(18.5)

Ethnicity

Akan

498(83.4)

99(16.6)

0.123 


\begin{tabular}{lll} 
Ga/Dangme & $57(82.6)$ & $12(17.4)$ \\
Ewe & $155(76.7)$ & $47(23.3)$ \\
Guan & $34(81.0)$ & $8(19.0)$ \\
Mole-Dagbani & $318(82.4)$ & $68(17.6)$ \\
Grussi & $72(79.1)$ & $19(20.9)$ \\
Gruma & $83(89.3)$ & $10(10.7)$ \\
Other & $56(90.3)$ & $6(9.7)$ \\
\hline
\end{tabular}

*P-values based on the Pearson chi-square test.

\section{Determinants of water intake}

Determinants of water intake are presented in Table 1. Women who were not consuming alcoholic beverages, were interviewed in September or October, were in the upper tertiles of the meat based dietary pattern, and were either underweight or had normal BMI were at risk of not meeting the recommended daily intake of water of 8 glasses or more per day.

Discussion

In this national representative sample, younger women, women from low income households, and poorer places of residence were associated with inadequate water intake. This finding is similar to other studies: which indicate higher water consumption for women in their 40s as compared to those in their 20s (Rosinger \& Herrick, 2016), and higher risk of inadequate water intake in Lower-income adults as compared to higher-income adults (Brooks, Gortmaker, Long, Cradock, \& Kenney, 2017). This buttresses the notion that socioeconomic disparities in inadequate water intake are related to differences in water intake (Brooks et al., 2017), which may point to unequitable access to portable water. The socio economic status though vital, did not remain significant in the multiple logistic regression.

The association of underweight women not meeting and overweight/obese women meeting their daily recommended intake may suggest that people who take less/more food or other nutrients turn to do same for water (Bankir, Perucca, Norsk, Bouby, \& Damgaard, 2017). The results further indicate that seasonality is a key determinant for water intake as women interviewed in November, which is relatively a dryer and warmer month across the country, turn to take in more water than those interviewed in September and October which are relatively moist.

Our findings on consumption of alcoholic beverages being a determinant of adequate water intake is similar to some findings in Japan, Germany, and Spain on the contribution of fluids to total food intake (Guelinckx et al., 2015). The diuretic effect of alcohol might be a contributive factor for water intake in this dietary pattern. Although this finding is positive for alcohol, considering the negative health risks associated with alcohol consumption, excessive intake of alcohol should not be encouraged. Dietary 
patterns are associated with water intake; it is thus not surprising that individuals in the middle tertile of the meat based dietary pattern turn to consume less water.

The strengths of this study include the use of a nationally representative sample. Additionally, it serves as a possible basis for studies on total water intake and the association between water intake and development of diseases. To the best of our knowledge this is the first study to investigate the socio-economic/ demographic factors and dietary patterns influencing water intake of Ghanaian women at the national level.

Authors acknowledge limitations in our study. The Ghana demographic and health survey was not originally designed for detailed water intake assessment as such only quantitative data on plain water intake were obtained. However, Ghana's Ministry of Health recommendation on the number of glasses of water intake per day accommodated for this limitation. The current findings are based on old data set (10 years) though it is the latest national data with water intake for women, it is possible it may not represent current intakes. Further studies are needed to confirm the present findings and to ascertain whether or not water intake has changed over the past decade. The application of this results may be limited to settings similar to Ghana.

\section{Conclusion}

Seasonality, some key socio-economic/demographic factors and dietary patterns were identified as determinants of water intake. These findings are hoped to provide scientific bases to guide interventions, recommendations, and policy programs targeted at women in Ghana. Additionally, it serves as a model for further research and a possible basis for studies on total water intake and the association between water intake and development of diseases.

\section{References:}

1. Bankir, L., Perucca, J., Norsk, P., Bouby, N., \& Damgaard, M. (2017). Relationship between sodium intake and water intake: The false and the true. Annals of Nutrition and Metabolism, 70(Suppl. 1), 51-61.

2. Brooks, C. J., Gortmaker, S. L., Long, M. W., Cradock, A. L., \& Kenney, E. L. (2017). Racial/ethnic and socioeconomic disparities in hydration status among US adults and the role of tap water and other beverage intake. American journal of public health, 107(9), 13871394.

3. Campbell, S. (2004). Dietary Reference Intakes: Water, potassium, sodium, chloride, and sulfate. Clinical Nutrition Insight, 30(6), 1-4.

4. Drewnowski, A., Rehm, C. D., \& Constant, F. (2013a). Water and beverage consumption among adults in the United States: Cross- 
sectional study using data from NHANES 2005-2010. BMC Public Health, 13(1), 1068.

5. Drewnowski, A., Rehm, C. D., \& Constant, F. (2013b). Water and beverage consumption among children age $4-13 y$ in the United States: analyses of 2005-2010 NHANES data. Nutrition journal, 12(1), 85.

6. EFSA Panel on Dietetic Products, N., \& Allergies. (2010). Scientific opinion on dietary reference values for water. EFSA Journal, 8(3), 1459.

7. Electrolytes, I. o. M. P. o. D. R. I. f., \& Water. (2005). DRI, dietary reference intakes for water, potassium, sodium, chloride, and sulfate: National Academy Press.

8. Gandy, J. (2015). Water intake: validity of population assessment and recommendations. European journal of nutrition, 54(2), 11-16.

9. Gibson, S., \& Shirreffs, S. M. (2013). Beverage consumption habits "24/7" among British adults: association with total water intake and energy intake. Nutrition journal, 12(1), 9.

10. Grandjean, A. (2004). Water requirements, impinging factors and recommended intakes. ILSI North America, Hydration: Fluids for Life.

11. GSS. (2009). Ghana Demographic and Health Survey 2008. (pp. 1483): Ghana Statistical Service - GSS, Ghana Health Service - GHS, and ICF Macro.

12. Guelinckx, I., Iglesia, I., Bottin, J., De Miguel-Etayo, P., GonzalezGil, E., Salas-Salvado, J., . . . Bardosono, S. (2015). Intake of water and beverages of children and adolescents in 13 countries. European journal of nutrition, 54(2), 69-79.

13. Jéquier, E., \& Constant, F. (2010). Water as an essential nutrient: the physiological basis of hydration. European Journal of Clinical Nutrition, 64(2), 115.

14. Kant, A. K., Graubard, B. I., \& Atchison, E. A. (2009). Intakes of plain water, moisture in foods and beverages, and total water in the adult US population-nutritional, meal pattern, and body weight correlates: National Health and Nutrition Examination Surveys 1999-2006. The American journal of clinical nutrition, 90(3), 655-663.

15. Kleiner, S. M. (1999). Water: an essential but overlooked nutrient. Journal of the American Dietetic Association, 99(2), 200-206.

16. Manz, F., Wentz, A., \& Sichert-Hellert, W. (2002). The most essential nutrient: defining the adequate intake of water. The Journal of Pediatrics, 141(4), 587-592.

17. Organization, W. H. (2005). Nutrients in drinking water: Geneva: World Health Organization. 
18. Rosinger, A., \& Herrick, K. A. (2016). Daily Water Intake Among US Men and Women: 2009-2012: US Department of Health and Human Services, Centers for Disease Control and Prevention, National Center for Health Statistics.

19. Stern, D., Piernas, C., Barquera, S., Rivera, J. A., \& Popkin, B. M. (2014). Caloric beverages were major sources of energy among children and adults in Mexico, 1999-2012. The Journal of Nutrition, 144(6), 949-956.

20. Vieux, F., Maillot, M., Constant, F., \& Drewnowski, A. (2016). Water and beverage consumption among children aged $4-13$ years in France: analyses of INCA 2 (Étude Individuelle Nationale des Consommations Alimentaires 2006-2007) data. Public Health Nutr, 19(13), 23052314. 